\title{
Malhação - Viva a diferença: ampliação e ressignificação do shipp Limantha no Twitter
}

\section{Malhação - Viva a diferença: expansion and resignification of the shipp Limantha on Twitter}

Gabriela Borges ${ }^{1}$ e Daiana Sigiliano ${ }^{2}$

1 Professora e vice-coordenadora do Programa de Pós-Graduação em Comunicação da UFJF. Coordenadora do Observatório da Qualidade no Audiovisual e integrante da Rede Interinstitucional Euroamericana de Competência Midiática para a Cidadania (Alfamed), sendo coordenadora da equipe brasileira. E-mail: gabriela.borges@ufjf.edu.br 


\section{Resumo}

Este artigo tem como objetivo analisar as dimensões da literacia midiática propostas por Mihailidis (2014) presentes nos conteúdos compartilhados no Twitter pelos fãs do shipp Limantha, da telenovela infanto-juvenil Malhação - Viva a diferença (2018-2019). Além de serem compostas por diversas camadas interpretativas, as produções criativas ressaltam o domínio e a compreensão crítica dos fãs em relação às nuances narrativas da telenovela e à arquitetura informacional do Twitter, bem como a criação de estratégias de mobilização em torno de tópicos específicos.

Palavras-Chave

Literacia midiática, cultura de fãs, twitter, Malhação - Viva a diferença, Limantha.

\section{Abstract}

This paper aims to analyze the dimensions of media literacy as proposed by Mihailidis (2014) that are present in the content produced by fans of the shippment Limantha, of the children's soap opera Young Hearts Embrace diversity (2018-2019) and shared on Twitter. In addition to being composed of several interpretive layers, the creative productions emphasize fans dominance and critical understanding in relation to narrative nuances and Twitter informational architecture, besides the creation of mobilization strategies around specific topics.

\section{Key words}

Media literacy, fan culture, twitter, workout, Limantha. 
As práticas da cultura de fãs são norteadas pela análise crítica dos conteúdos midiáticos, abrangendo tanto o envolvimento emocional quanto intelectual. É feita por meio da curadoria, da seleção e distribuição de conteúdos online, e da resistência, na ressignificação dos universos ficcionais e em mobilizações relacionadas às questões sociais e ao cancelamento das tramas (SANDVOSS, 2013). Thomas (2007) pontua que produções como, por exemplo, as fanfics, os vídeos on crack, a legendagem de vídeos e os memes envolvem diversas referências intertextuais, além de processos multimodais e polissêmicos. O autor afirma que, independente da prática, os conteúdos são pautados por um profundo conhecimento do universo ficcional, não se restringindo a um relato superficial da atração. Nesse sentido, os fãs exploram distintas perspectivas do paratexto ao avaliar, participar, distribuir e remixar conteúdos.

Ao compreender criticamente as tramas e produzir conteúdos, os fãs estabelecem um nítido diálogo com a literacia midiática. Segundo Livingstone (2007, p. 27) a literacia midiática se refere "[...] a capacidade de acessar, analisar, avaliar e criar mensagens através de uma variedade de contextos diferentes"3 $^{\prime 3}$ (tradução nossa). Dessa forma, os fãs engendram novos modos de aprendizagem no ambiente de convergência, tais como a curadoria, a troca de conhecimento em rede, a colaboração no desenvolvimento de conteúdos, a distribuição das produções em plataformas on-line etc. Como ressaltam Massarolo e Mesquita (2013, p. 35), "[...] a produção dos fãs abrange tanto a interpretação textual quanto os comentários, análises, ensaios opinativos e boletins explicativos, permanecendo aberta ao compartilhamento de arquivos e à pluralidade de opiniões".

A partir deste contexto, este artigo procura discutir as relações entre a literacia midiática e a cultura de fãs tendo como objetivo de análise o arco dramático das personagens Lica e Samantha da vigésima quinta temporada da 
telenovela infanto-juvenil Malhação (1995-atual, Rede Globo), intitulada Viva a diferença (2018-2019). O enquadramento teórico-metodológico para a análise da produção dos fãs a partir do shipp Limantha no Twitter é construído tendo em conta o conceito de Twitter literacy (GREENHOW; GLEASON, 2012) e as dimensões da literacia midiática propostas por Mihailidi (2014) para entender a riqueza e complexidade das competências em operação nestas formas de expressão dos fandoms. São elas: a curadoria (a capacidade de organizar e sistematizar conteúdos multimídia), a criação (capacidade de produzir, remixar e compartilhar conteúdos em plataformas online), a compreensão crítica (capacidade de analisar e compreender criticamente os conteúdos em rede), a participação (capacidade de comentar, editar e propagar publicações em diferentes plataformas) e a colaboração (capacidade de produzir, de modo colaborativo, conteúdos relevantes).

\section{A literacia midiática na conversação em rede}

O atual ecossistema de conectividade propicia a expansão do conceito de literacia midiática, engendrando diversas abordagens. Como sugere Passarelli (2010, p. 73) "Na passagem da cultura letrada à cultura das mídias e da convergência, marcada pela não linearidade e pela interatividade, o conceito de literacia se expande, abrangendo as competências do usuário para explorar esse potencial multimídia". De acordo com Dinehart (2008), Scolari (2016) e Jenkins et al. (2009) o ambiente da cultura da convergência demanda novas práticas comunicativas relacionadas à literacia midiática, tais como a realização de tarefas simultâneas (multitarefa), a cognição distribuída (capacidade de interagir significativamente com ferramentas que expandem as habilidades mentais), a inteligência coletiva e a navegação transmídia.

De modo geral, as discussões sobre estas habilidades sociais de interação em plataformas colaborativas podem ser divididas em três eixos: as capacidades comunicativas dos jovens nas redes sociais digitais (ALVERMANN; HAGOOD, 2000; HIRSJÄRVI, 2013; HERRERO-DIZ, 2017); a promoção da 
cidadania (KELLNER; SHARE, 2005) e o incentivo e desenvolvimento de ações educativas no âmbito escolar (ROJO, 2012). Autores como Gilster (1997) e Scolari $(2016,2018)$ ressaltam a necessidade de delimitar termos específicos para a reflexão da literacia midiática no atual ecossistema de convergência. Gilster (1997) propõe o conceito de alfabetização digital para se referir à capacidade comunicativa de compreender e criar conteúdos online em diferentes formatos a partir de uma ampla variedade de fontes. Em outras palavras, o autor destaca as habilidades de buscar, processar, comunicar e produzir em plataformas digitais, englobando tanto o conhecimento técnico quanto o entendimento crítico (GILSTER, 1997).

Para Scolari $(2016,2018)$ as discussões presentes na literacia e na literacia midiática não abarcam a complexidade e as práticas de produção e consumo contemporâneos. Neste sentido, o autor $(2018$, p. 8$)$ adota o conceito de transmedia literacy (literacia transmídia) para analisar o "[...] consumo de media digitais interativos, que vão desde processos de resolução de problemas em videojogos até a produção e partilha de conteúdo em plataformas web e redes sociais". Um dos pontos centrais da proposta teórica de Scolari (2018) é a leitura polissêmica e informal dos meios, ou seja, além permear por distintas plataformas os sujeitos são dotados do que o autor cunha como estratégias de aprendizagem informal.

Os fãs sempre estiveram na vanguarda na adoção de novas tecnologias, sites e redes sociais digitais. Plataformas como, por exemplo, Usenet, blogs, listas de e-mails e BBS (Bulletin Board Systems) foram fundamentais na troca de informações e na produção e propagação dos conteúdos da cultura de fãs. Como pontua Coppa (2017, p. 295-296),

Depois das conferências de tecnologia da O'Reilly, muitas pessoas começaram a falar sobre a 'web 2.0 ' e 'mídia social' e 'conteúdo gerado pelo usuário', o que parecia muito com aquilo que os fãs já faziam naturalmente [...] os fãs sempre foram impulsionadores da tecnologia e já se comunicavam entre si através de toda plataforma concebível. 
Nesse sentido, o ambiente de convergência amplia as possibilidades de criação e distribuição das práticas do público ávido. Se nas décadas de 1970 e 1980 os fãs organizavam convenções, produziam newsletters e fanzines que eram enviadas pelo correio se restringindo a um grupo limitado de pessoas, na contemporaneidade as práticas ganham novos desdobramentos e visibilidade, podendo ser repercutidas por inúmeros fãs.

Jenkins et al. (2014, p. 57) afirmam que o Twitter foi rapidamente adotado pelos fandons por propiciar não só novos modos de interagir social e culturalmente, mas também pela "[...] eficiência com que esse site facilita os tipos de compartilhamento de recursos, de conversações e de coordenação que as comunidades vêm usando há muito tempo". Assim como outras redes sociais, tais como o Facebook e o Tumblr, o microblogging é norteado pela conversação em rede, isto é, uma nova forma conversacional, mais pública, coletiva e rastreável (RECUERO, 2014). De acordo com Recuero (2014, p. 17-18) as conversas presentes nas redes sociais digitais "[...] influenciam a cultura, constroem fenômenos e espalham informações e memes, debatem e organizam protestos, criticam e acompanham ações políticas e públicas".

A conversação em rede tem como uma de suas características centrais a multimodalidade, o recurso pode ser observado tanto no conteúdo quanto na organização e na estrutura dos tweets. Como pontua Recuero (2014) as postagens podem agregar diversas interfaces, tais como a audibilidade e a visualidade. Durante a exibição da telenovela Amor de Mãe (2019-2020, Rede Globo), por exemplo, os telespectadores interagentes (SIGILIANO; BORGES, 2019) repercutiram o arco narrativo envolvendo os personagens (Humberto Carrão) e Betina (Isis Valverde). Nos tweets, os fãs ressaltaram a falta de química do casal e criticaram o desdobramento do folhetim através da multimodalidade, ou seja, usando formas de linguagem escrita (texto) e visual (imagem). 


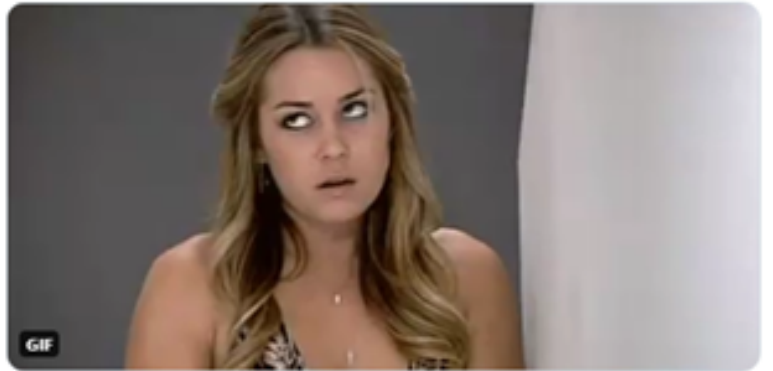

10:22 PM - 16 de mar de 2020 - Twitter for Android

124 Retweets 592 Curtidas

Figura 1: No mesmo tweet distintas formas de linguagem coexistem, temos o texto e o GIF. Fonte: Twitter (2020)

Conforme destaca Recuero (2014) esta coexistência de linguagens não é o único modo de multimodalidade, o recurso também norteia a conversação síncrona, aquela que os interagentes estão conectados à rede social simultaneamente, e assíncrona, que não é pautada pela copresença. Segundo Recuero (2014) a conversação em rede propiciou o compartilhamento instantâneo de conteúdo. No Twitter, especificamente, as hashtags (\#) facilitaram, por exemplo, novas conexões entre os fãs possibilitando mobilizações em torno de tópicos. Tais como as campanhas contra o cancelamento ${ }^{4}$ das séries, o apoio ${ }^{5}$ a participantes de reality shows, entre outros. Outro ponto é a possibilidade de migração da conversa (RECUERO, 2014). Ou seja, uma postagem pode começar em uma rede social e se desdobrar em outra, além de alternar entre pública e privada. Em outras palavras, uma discussão iniciada em um grupo privado de fãs no Facebook reverbera no Twitter, envolvendo diversos interagentes.

O modo como os fãs adotam o Twitter para se mobilizar, repercutir, ampliar e ressignificar os conteúdos midiáticos está relacionado com o conceito de Twitter 
literacy. O termo integra os novos modos de aprendizado do ambiente da cultura da convergência, abrangendo as práticas comunicativas e criativas dos interagentes no microblogging. Os autores destacam que o Twitter estimula o compartilhamento, a colaboração, a leitura atenta, a resolução de problemas, a sistematização de informação e a produção de conteúdos a partir de várias linguagens. Nesse contexto, a rede social introduz novas habilidades, tais como a multimodalidade, a filtragem de informações e a colaboração em rede. O Twitter literacy estabelece uma interrelação entre a compreensão crítica, abrangendo a arquitetura informacional e a interpretação dos conteúdos repercutidos no microblogging, e a produção criativa, através da publicação de tweets, explorando interfaces híbridas e polissêmicas, elaborados coletivamente em rede.

\section{O fandom de Limantha}

No ar em sua 27a temporada, a telenovela Malhação foi criada em 1995 por Andréa Maltarolli e Emanuel Jacobina, com a direção de Roberto Talma. Exibida na TV Globo de segunda-feira a sexta-feira, entre às $17 \mathrm{~h} 30$ e $18 \mathrm{~h}$, cada temporada se organiza a partir de um arco narrativo central, incluindo personagens, ambientação e as pautas que serão discutidas. Apesar de hoje tratar de temas como, por exemplo, o preconceito, o feminismo, o bullying e o racismo, inicialmente o programa tinha como objeto abordar

[...] histórias sem muita profundidade e que atinjam diferentes faixas etárias. A ideia é criar acontecimentos rápidos a cada capítulo, que atraiam, entre outros, o público jovem. Mas a emissora não quer discutir problemas da juventude já que pretende direcionar Malhação a um público diversificado (TV FOLHA, 1995, online).

Desenvolvida por Cao Hamburger, a vigésima quinta temporada de Malhação, intitulada Malhação - Viva a diferença (2017-2018), gerou altos índices de audiência e mobilizou os telespectadores nas redes sociais. Pela primeira vez, em 25 anos de exibição, a atração foi protagonizada por cinco mulheres. O principal arco narrativo se desdobra após as adolescentes Keyla (Gabriela Medvedovski), 
Benê (Daphne Bozaski), Tina (Ana Hikari), Lica (Manoela Aliperti) e Ellen (Heslaine Vieira), de origens e perfis distintos, ficarem presas no mesmo vagão de metrô durante uma pane elétrica causada por uma tempestade que atinge a cidade de São Paulo. O plot tem início quando a personagem Keyla entra em trabalho de parto e as adolescentes se unem em solidariedade para ajudá-la no nascimento do bebê.

Como destaca a reportagem de Peccoli (2018) a temporada, exibida entre maio de 2017 e março de 2018, alcançou 20,4 pontos e 37\% de participação, atingindo a maior média de audiência desde 2009. Ao longo da trama o público compartilhava suas impressões nas redes sociais, principalmente no Twitter, e ressignificava o universo ficcional através de memes e vídeos. Para engajar os telespectadores interagentes, a Rede Globo desenvolveu uma série de ações nas plataformas digitais que apresentavam novas perspectivas da trama (BORGES et al., 2019). O último capítulo da temporada, exibido em 5 de março de 2018, gerou mais de 299 mil tweets e a hashtag \#VivaADiferença atingiu os Trending Topics mundial, ficando entre os assuntos mais comentados do microblogging (PECCOLI, 2018).

Um dos arcos narrativos mais repercutido entre os fãs da trama foi do casal Lica e Samantha (Giovanna Grigio), pela primeira vez a telenovela exibiu um beijo entre duas meninas bissexuais. A cena, exibida em dezembro de 2017, repercutiu de maneira instantânea nas redes sociais e as personagens ganharam fãs no mundo todo. Nomeado pelo fandom como Limantha, o shipp é o acrônimo dos nomes de Lica e Samantha. O shipp foi ampliado, aprofundado e ressignificado através de diversas práticas da cultura de fãs, tais como fanfic, vídeos on crack, fanarts, entre outros.

De acordo com Sigiliano e Borges (2016), e Fechine e Cavalcanti (2017), Malhação está atualmente entre os programas da Rede Globo que mais geram engajamento nas redes sociais. Porém, apesar das ações desenvolvidas pelo canal para a telenovela atingirem métricas mais altas em relação às postagens sobre outras atrações da Globo, o que se observa, no âmbito da cultura de fãs, 
é a baixa adesão das estratégias propostas, como, por exemplo, o que ocorreu com as hashtags postadas pela emissora durante a exibição de Malhação. Fechine e Cavalcanti (2017) sugerem que os fãs criam suas próprias indexações para repercutirem os capítulos ao invés de adotarem as indexações lançadas pelo canal. Nesse contexto, a "[...] falta de adesão dos fãs à hashtag da emissora explica-se, muitas vezes, pela falta de identificação dos internautas com o tópico conversacional, com o personagem ou episódio da narrativa que a emissora quer destacar" (FECHINE; CAVALCANTI, 2017, p. 199).

\section{A literacia midiática e o fandom Limantha}

Para analisar a produção do fandom de Limantha no Twitter sob a perspectiva da literacia midiática, foi construída uma proposta metodológica de monitoramento, codificação, organização e análise dos dados composta por quatro etapas (FRAGOSO; RECUERO; AMARAL, 2011; BRUNS; MOE, 2013; RECUERO; BASTOS; ZAGO, 2015; SIGILIANO; BORGES, 2019). A primeira etapa foi feita em dezembro de 2017 e consistiu na navegação sistemática pelos perfis para a delimitação das páginas que seriam monitoradas. Para isso, inserimos na barra de busca ${ }^{6}$ do Twitter, vinculada à sua API ${ }^{7}$, os termos (palavras-chave e hashtags) relacionados ao universo ficcional de Malhação Viva a diferença. Como, por exemplo, o nome da temporada, dos personagens e do shipp. Com base nos resultados ${ }^{8}$ os perfis foram selecionados a partir dos recursos de individualização e das camadas estruturais de informação (RECUERO, 2009; BRUNS; MOE, 2013). Desta forma, os perfis tinham que apresentar recursos estéticos e de conversação relacionados ao shipp Limantha. Na navegação sistemática observamos se as páginas eram compostas por pelo menos dois dos quatro recursos de individualização (avatar, capa, username

6 Disponível em: https://twitter.com/search-advanced. Acesso em: 7 dez. 2017.

$7 \quad$ Application Programming Interface. 
e descrição). Os itens tinham que fazer alguma alusão a Lica e Samantha. O outro critério usado na seleção dos perfis que seriam monitorados se refere às camadas estruturais de informação. Conceituada por Bruns e Moe (2013) essa categorização estabelece diferentes níveis de conversação do Twitter, são eles micro ${ }^{9}$, meso ${ }^{10}$ e macro ${ }^{11}$. Nesse modo, foram observados se os conteúdos, as menções e as indexações postadas pelos telespectadores interagentes faziam referência ao casal. A partir dessa filtragem chegamos ao recorte de $40^{12}$ perfis ativos relacionados ao universo ficcional de Limantha.

A segunda etapa esteve focada no monitoramento e na extração dos tweets, e se dividiu em dois momentos. Durante a exibição dos capítulos da telenovela que abordavam o arco narrativo de Lica e Samantha (de 21 dezembro de 2017 a 5 março de 2018) e após o encerramento da atração (de 6 de março de 2018 a 10 maio de 2018). Para visualizar os tweets postados durante a exibição dos capítulos adotamos o TweetDeck ${ }^{13}$, um aplicativo nativo do microblogging, que espelha e atualiza em tempo real todas as postagens dos 40 perfis. Conforme já adotamos em outros trabalhos, devido ao grande volume de dados, optamos por capturar os conteúdos com um screen capture software ${ }^{14}$ (BORGES et al., 2017; SIGILIANO; BORGES, 2019). No segundo momento, com o fim da temporada, os usuários que ele troca mensagens etc. (BRUNS; MOE, 2013). esta questão (BRUNS; MOE, 2013). @BestaEhTu, @comamorjonas, @shipper_clexa, @bxenough, @joabuttercup, @mnksboy, @zgrigio, @fetishforkcc, @cabellarys, @cabelloreasons, @clarkegriffrn, @cmilacores, @lambertiniSmantha, @Gutierrez_Heloísa, @limanthamor, @mottajauregui, @rosanas1a2n3, @seemslikebabs, @spotifybea, @TagsLimantha, @limanthagifs, @portalgripert, @portallimantha, @limanthasbr, @manoelaupdate, @LimanthaFalando, @shippowlimantha, @Limantha18, @archivegripert, @projetomvad, @MAVADasSpotify, @mvadout. 
em 5 de março de 2018, o monitoramento foi ampliado, se estendendo até o dia 10 de maio de 2018.

A terceira etapa consistiu na codificação dos tweets extraídos durante o monitoramento, ao todo foram coletadas 392 mil postagens. Nesta fase, os tweets foram identificados, descritos e categorizados manualmente, isto é, cada post foi analisado de forma individual, sem a ajuda de softwares (FRAGOSO; RECUERO; AMARAL, 2011; RECUERO; BASTOS; ZAGO, 2015; SIGILIANO; BORGES, 2019). Agrupando os tweets de acordo com suas idiossincrasias, em busca de similaridades, dissimilaridades, padrões e peculiaridades (FRAGOSO; RECUERO; AMARAL, 2011). Por conta do volume e complexidade dos dados, a codificação foi dividida em duas fases: macro e microcodificação. Inicialmente, categorizamos as postagens a partir dos contextos conversacionais, isto é, o tema central da publicação. Dessa forma foram identificadas 48 categorias na macrocodificação tais como, por exemplo, 'elogios', 'questões sociais', 'interação com o elenco da trama' etc. Ou seja, na macrocodificação 'questões sociais', por exemplo, buscamos as questões (LGBTQI+, racismo, feminismo e etc.) que os fãs repercutiam. Na microcodificação a categorização foi norteada pelo conteúdo específico de cada contexto, tendo sido levantadas 195 categorias. É importante ressaltar que as categorias da microcodificação não são excludentes, dessa forma um único tweet pode constar em mais de uma categoria.

A quarta etapa consistiu na análise dos conteúdos postados no Twitter pelo fandom do casal Lica e Samantha a partir das reflexões de Mihailidis (2014). O autor afirma que na contemporaneidade o desenvolvimento de competências ultrapassa as lógicas tradicionais das mídias, abrangendo a interpretação crítica de conjuntos interativos e a integração de distintas plataformas. Mihailidis (2014) pontua que na cultura da convergência a literacia midiática engloba cinco habilidades: a curadoria, a criação, a compreensão crítica, a participação e a colaboração. Entretanto, como o autor destaca, as dimensões estão interrelacionadas e esta separação é feita para que possamos analisar didaticamente cada uma delas. 
A habilidade da curadoria envolve a capacidade de organizar, filtrar, selecionar e sistematizar conteúdos. O autor ressalta que a curadoria ganhou novas possibilidades no ambiente de convergência como, por exemplo, o compartilhamento de links, a criação de threads e a elaboração de tutoriais. Os perfis monitorados não só produziam conteúdos tais como wallpapers, vídeos on cracks, threads explicativas sobre a trajetória dos personagens, packs de ícones para smartphones, pastas colaborativas com os downloads das cenas editadas, playlists no Spotify, repositório de capítulos e etc, como também mobilizavam outros interagentes em torno de tópicos conversacionais específicos (acontecimentos dos capítulos, projeção dos personagens, protestos contra os roteiristas e etc.). Nesse contexto, os fãs eram amplamente conhecidos no fandom de Limantha por reunirem informações e conteúdos sobre o universo ficcional e por gerarem fluxo instantâneo na rede.

A habilidade de criação envolve a capacidade de produzir, remixar, compartilhar e integrar conteúdos em plataformas online (MIHAILIDIS, 2014). Conforme já discutimos em outros trabalhos (BRANDÃO et al. 2016, BORGES et al. 2017), a criação de perfis fictícios dos personagens no Twitter é uma prática recorrente entre os fãs de telenovela. As páginas não só reforçam, mas também ampliam o universo ficcional das tramas, explorando novos desdobramentos da história. Apesar de a sexualidade ser um dos temas norteadores na construção do arco narrativo de Limantha, por conta do horário, da faixa etária e de integrar uma trama com diversos personagens, o assunto foi brevemente abordado na atração da TV Globo. Durante a exibição de Malhação - Viva a diferença foram criados dez perfis fictícios dos personagens e, de modo geral, as páginas aprofundavam questões que não eram desenvolvidas na telenovela.

O perfil de Samantha, o @lambertiniSmantha, explorava, entre outros temas, tais como o relacionamento com Lica e o acidente de Anderson (Juan Paiva), o medo de falar sobre a sua orientação sexual com os pais. Em uma postagem realizada em março de 2018, o fã integrou duas redes sociais: o Twitter e o Instagram. No Instagram fictício da personagem o fã postou uma foto de 
Samantha em uma praia com a seguinte legenda: Pelo olhar da minha musa @Gutierrez_Heloísa. Minutos depois, o perfil da adolescente no microblogging relatava que tinha acabado de postar uma foto em que se declarava para Lica no Instagram e que estava com receio da reação dos pais. O tweet foi retuitado (RT) por alguns telespectadores interagentes de Malhação relatando que também compartilhavam da insegurança da personagem. Neste contexto, o fã aprofundava questões delicadas que não eram amplamente exploradas na telenovela e, mesmo que indiretamente, pontuava as diferentes abordagens do Instagram e do Twitter. Se no microblogging o perfil fictício expunha o seu receio de conversar sobre a bissexualidade com a família, no Instagram a adolescente contornava o medo e se declarava para Lica.

Assim como os demais personagens da temporada Viva a diferença Samantha adorava música e tinha uma banda, Os Lagostins. Formado pela adolescente, Felipe (Gabriel Calamari), MB (Vinicius Wester) e Guto (Bruno Gadiol) o grupo protagonizava várias ações transmídia da telenovela. Os clipes eram exibidos na íntegra no site do GShow e tinham seus áudios disponibilizados pelos fãs, mesmo que ilegalmente, para download.

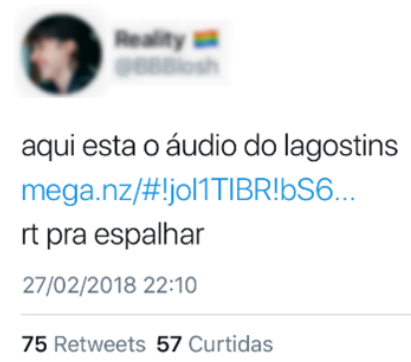

Figura 2: O fã reproduz compartilha o áudio de uma das músicas dos Os Lagostins. Fonte: Twitter (2018)

O último clipe lançado pelos Os Lagostins, na trama, foi um cover de Gente Aberta, composta por Erasmo Carlos e Roberto Carlos em 1971. Na história, Samantha dedica a canção para Lica. Porém, na atração televisiva só vemos a versão final do clipe, não acompanhamos de maneira detalhada a escolha do 
cover, as gravações e etc. A partir deste arco narrativo, o perfil @MVADasSpotify reproduziu a interface da plataforma YouTube. Entre os conteúdos que compõem a montagem está um vídeo com a versão acústica de Gente Aberta, como se a adolescente estivesse ensaiando. A reprodução da interface do YouTube contém vários elementos característicos da arquitetura informacional do site como, por exemplo, o número de visualizações, o nome e o avatar do usuário e o tempo de duração do vídeo. Ao preencher as lacunas deixadas na telenovela, o fã aproxima a personagem dos hábitos comuns de qualquer adolescente, que posta seus vídeos na rede social, que tem um perfil no YouTube, além de demonstrar a sua expertise na compreensão dos elementos que integram a plataforma.

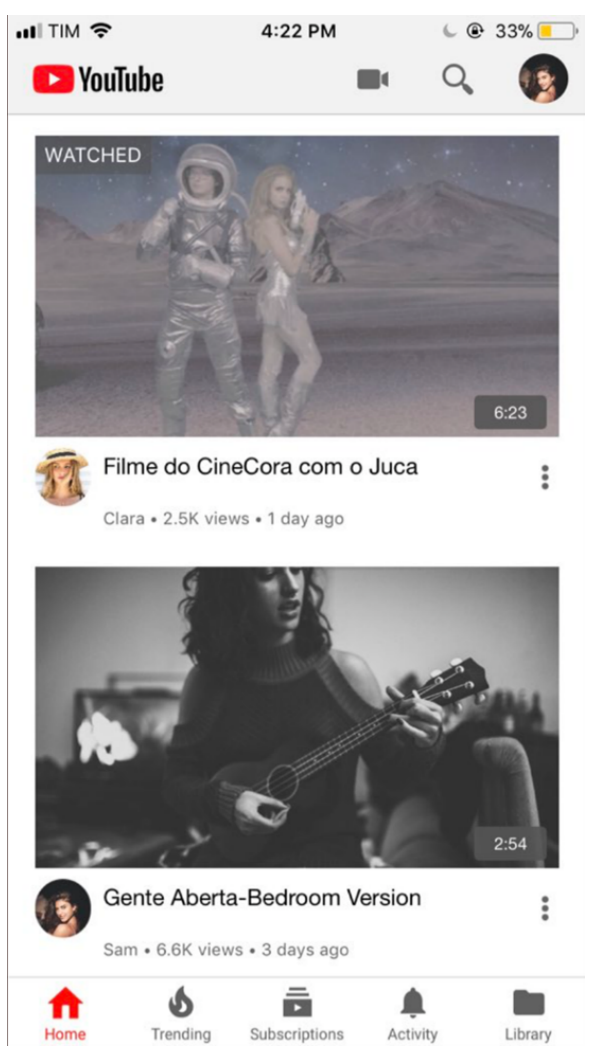

Figura 3: O fã reproduz a interface do YouTube, além das informações sobre o vídeo de Samantha ensaiando Gente Aberta, o curta dos personagens Juca e Clara.

Fonte: Twitter (2018)

A habilidade da compreensão crítica se refere, segundo Mihailidis (2014), à capacidade de analisar e compreender criticamente os conteúdos como, por exemplo, 
o entendimento de mensagens, formato e gêneros a partir de suas semelhanças e especificidades. Em Malhação - Viva a diferença o núcleo familiar de Samantha integrou diversas práticas do fandom Limantha, tais como fanfics, vídeos on crack e fanarts (OBSERVATÓRIO DA QUALIDADE NO AUDIOVISUAL, 2019). Apesar de ser citado brevemente em algumas sequências da telenovela, os pais e a casa da personagem não chegaram a ser exibidos na TV, apenas sugeridos esporadicamente. Como, por exemplo, quando Samantha diz a Anderson que seu pai está no trabalho e a sua mãe está viajando e, por isso, eles poderiam ir para a casa dela. A falta de informações substanciais sobre o arco narrativo despertou a curiosidade nos fãs. No Twitter eles completavam as brechas deixadas no cânone, ampliando o universo ficcional. Exibida no dia 6 de fevereiro de 2018 a cena em que o casal discute por causa do fim do relacionamento de Bene e Guto gerou buzz na rede social não só pela troca de ofensas entre as personagens, mas também pelo destino de Samantha.

Na cena, a adolescente vai embora da casa de Lica no meio da noite, porém não acompanhamos a volta da personagem para casa, o arco se desenvolve apenas com Marta (Malu Galli) conversando com a filha sobre a saída abrupta da namorada. No microblogging o fandom começou, a partir da sequência, a repercutir para onde a personagem iria. Os memes criados pelos fãs mostravam o quadro em close e ressignificavam o espanto de Samantha, causado no paratexto pela resposta agressiva de Lica, como se a adolescente estivesse na verdade preocupada com o seu destino. Diante da lacuna deixada pelos roteiristas os fãs ironizam a situação da personagem, afirmando que ela não tinha casa para voltar já que esta nunca apareceu na telenovela.

De acordo com Jamison (2017) a intertextualidade é um aspecto recorrente nas práticas da cultura de fãs. A autora cita o conceito de dupla codificação de Eco (2002) para descrever a produção criativa dos fandons que comunicam tanto com o público casual quanto com o público ávido. Isto é, o contexto geral pode ser compreendido por aqueles que não têm conhecimento aprofundado sobre o assunto, mas algumas referências só serão reconhecidas e entendidas em sua totalidade pelos fãs. Os memes produzidos pelo fandom Limantha apresentavam este código duplo, além 
da expressão assustada de Samantha ao se dar conta que não tinha para onde ir, os tweets faziam uma correlação com a personagem de Giovanna Grigio na telenovela Chiquititas (2013-2015, SBT). Na trama a atriz interpretava Mili, uma órfã do Orfanato Raio de Luz. As publicações ironizam o cânone afirmando que já que a adolescente não tinha casa, o único lugar para o qual ela poderia ir seria para o orfanato.

O contexto conversacional discutido pelo fandom ressalta que, ao compreender criticamente o universo ficcional, o grupo consegue identificar as lacunas no cânone e desenvolver possíveis desdobramentos que não estão na telenovela. A partir da sequência os fãs fazem uma correlação entre o arco narrativo de Mili, de Chiquititas e o de Samantha, de Malhação - Viva a diferença. Entretanto, o ponto de interseção entre os universos não é somente a atriz Giovanna Grigio, mas o diálogo entre a lacuna percebida pelos fãs e o arco narrativo de Mili, que envolve temas como a família, o orfanato, o abandono etc. Dessa forma, o fandom consegue buscar referências que vão além da telenovela da TV Globo, estabelecendo várias camadas interpretativas.

\section{quando tu lembra que não tem casa e o único lugar que pode ir é o orfanato raio de luz}
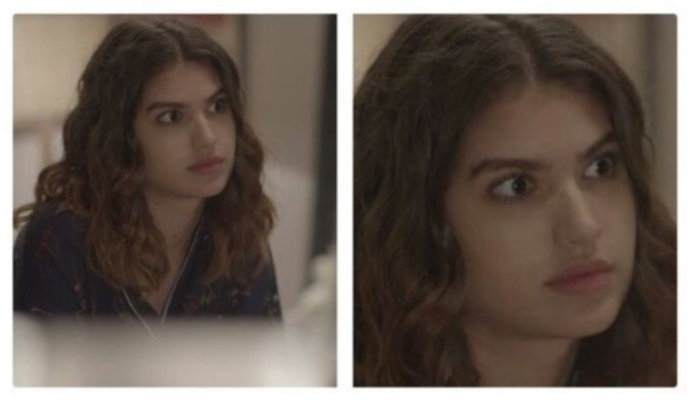

Figura 4: O tweet ressignifica a reação de Samantha e ironiza o universo ficcional de Malhação - Viva a diferença fazendo uma referência a trama de Chiquititas (2013-2015, SBT).

Fonte: Twitter (2018). 
Com base na personalidade de Lica e Samantha o fandom também inseria as adolescentes em acontecimentos reais. Como, por exemplo, a polêmica ${ }^{15}$ envolvendo o Queermuseu. Os fãs afirmavam que como Lica era ativista e gostava de arte, com certeza estaria à frente dos protestos a favor da exposição. O mesmo pôde ser observado nos eventos relacionados à eleição presidencial de 2018. Os tweets ressaltavam que o casal participaria do movimento \#EleNão ${ }^{16}$ em prol da comunidade LGBTQI+ e da igualdade de gênero, estabelecendo um diálogo entre a ficção e a realidade.

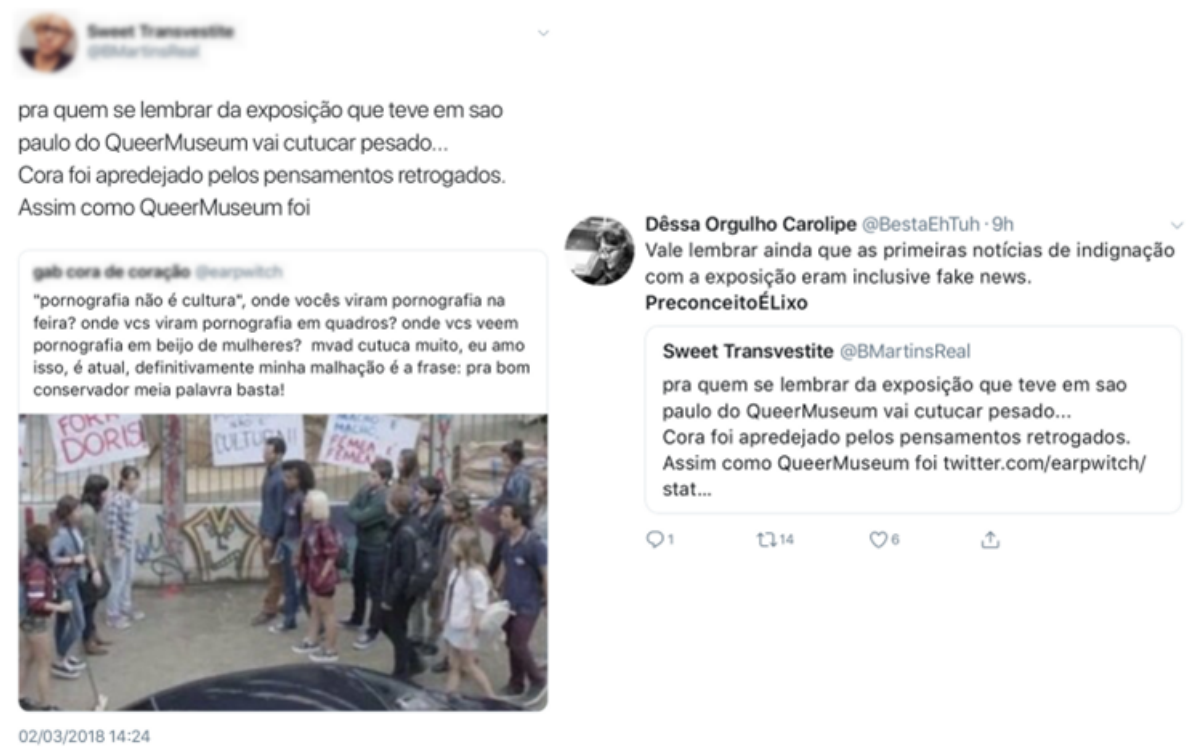

Figura 5: Os fãs repercutem o caso do Queermuseu a partir do arco narrativo do Cora Coralina. Na trama, a escola é alvo das fake news e do discurso conservador.

Fonte: Twitter (2018)

A habilidade da participação abrange a capacidade de comentar, editar e propagar publicações em diferentes plataformas colaborativas, tais como fóruns e redes sociais (MIHAILIDIS, 2014). Conforme ressaltamos ao longo deste artigo as questões relacionadas à comunidade LGBTQI+ estavam implícitas no 
desenvolvimento do arco narrativo de Limantha. Porém, a faixa etária recomendada, a proposta da trama de Cao Hamburger e, principalmente, por assunto ainda ser tratado como tabu na televisão nacional, as nuances do relacionamento das personagens não eram aprofundadas. As críticas dos fãs eram unânimes no Twitter, o público pedia que Lica e Samantha falassem abertamente sobre a sua sexualidade e que os beijos e as trocas de carícias entre as adolescentes fossem retratados da mesma forma que dos casais heterossexuais. Estes pontos do cânone reverberaram no microblogging não só através da produção criativa do fandom, mas também de protestos durante a exibição da telenovela.

Desde o início do desenvolvimento do arco narrativo protagonizado por Lica e Samantha, em dezembro de 2017, os fãs se mobilizaram em torno de hashtags específicas para comentarem os desdobramentos do casal na rede social. As indexações criadas pelo fandom faziam alusão ao principal acontecimento envolvendo as personagens no capítulo que estava no ar. A escolha da hashtag era mediada pelo perfil @TagsLimantha por meio de uma enquete. No dia anterior os fãs sugeriam, com base na sinopse do capítulo publicado no GShow, as possíveis indexações. As três hashtags escolhidas pelo perfil iam para votação e a mais votada era divulgada pelo @TagsLimantha e adotada pelo fandom durante a exibição do capítulo no dia seguinte.

Entretanto, à medida que o relacionamento de Limantha foi sendo explorado na história, os fãs passaram a usar as hashtags para protestar contra os pontos do paratexto. Como, por exemplo, a indexação \#LimanthaSemCensura, usada no dia 15 de fevereiro de 2018, em que o fandom chamou a atenção para as diferenças entre as cenas de Lica e Felipe e Lica e Samantha. Segundo os fãs, nas sequências com o ex namorado a adolescente se aproximava, tocava nos ombros e nas mãos de Felipe. Em contrapartida, a interação com Samantha não tinha toque, apenas uma breve troca de olhares. A indexação gerou cerca de 31 mil tweets e ocupou a quarta posição nos Trending Topics (Brasil) da rede social. Lançada no dia 22 de fevereiro de 2017, a hashtag \#LGBTMereceRespeito também problematizava o modo como o arco narrativo das personagens era conduzido pela TV Globo. 
A mobilização do fandom foi repercutida por sites especializados como o Observatório do Cinema ${ }^{17}$, cuja reportagem destacava a inviabilização da bissexualidade,

Usuários da rede subiram uma hashtag chamada \#LGBTMereceRespeito, pois receiam que ao final da atual saga da novela, Samantha acabe ficando com o rapaz ao invés de Lica e que o namoro lésbico foi só passageiro. Críticas sobre a exploração do relacionamento das duas também aconteceram, alegando que não foi bem feito como são os casais heterossexuais (OBSERVATÓRIO DO CINEMA, 2018, online).

Intitulada pelos telespectadores interagentes de Ask Limantha, a ação promovida pelo @TagsLimantha propunha uma discussão coletiva no fandom. O perfil publicava uma pergunta e os fãs respondiam com base nos possíveis acontecimentos futuros da trama, usando a hashtag \#akslimantha. Como, por exemplo, qual faculdade Lica e Samantha estão fazendo. Depois de compartilharem trechos da trama e argumentarem sobre os principais interesses e aptidões das adolescentes os telespectadores interagentes chegaram à conclusão de que Lica fez Artes Plásticas e Samantha Arquitetura. As reflexões propostas no Twitter reverberaram nas fanfics, cujas tramas apresentam capítulos que se passam anos após a temporalidade do cânone, em que as personagens já estão formadas e morando fora do Brasil.

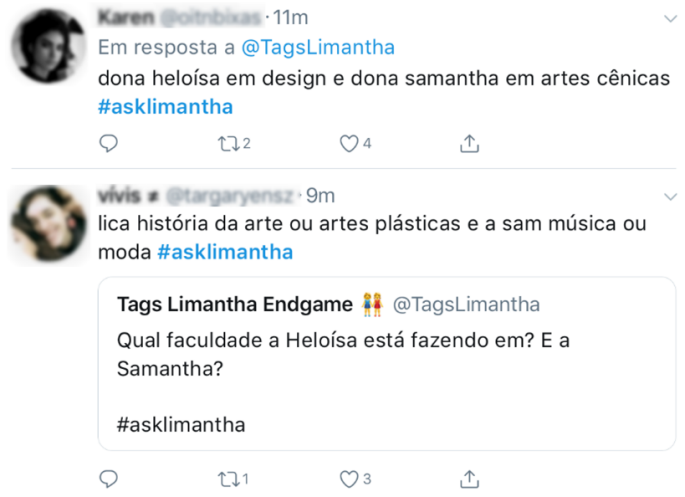

Figura 6: Os fãs participam do \#AskLimantha, fazendo projeções em relação do futuro das personagens.

Fonte: Twitter (2018). 
A habilidade de colaboração abarca a capacidade de produzir, de modo colaborativo, conteúdos relevantes, em que cada interagente colabora para o todo (MIHAILIDIS, 2014). Um ponto importante nas discussões sobre o arco narrativo de Limantha é que a elaboração das projeções que vão além do universo ficcional é coletiva. Ou seja, a partir de um questionamento, os fãs se mobilizam para juntos refletirem, com base no metatexto, sobre quais seriam as melhores possibilidades. No capítulo final de Malhação - Viva a diferença Lica e Samantha decidem fazer uma viagem pelo Brasil. Após o término da trama, os fãs deram continuidade ao plot, refletindo não apenas sobre as cidades que as personagens estavam visitando, mas como estaria a relação delas com os amigos. As ampliações dos potenciais ressignificavam imagens feitas nos bastidores da trama como, por exemplo, a foto tirada no intervalo das gravações do aniversário de Tonico, filho de Keyla, em que vemos Lica, Samantha, Tina e Anderson. Ao publicarem a imagem no Twitter os fãs afirmavam que a foto registrava um jantar que as adolescentes tinham organizado para contarem ao casal de amigos os detalhes sobre a viagem.

\section{Considerações finais}

A conversação em rede propicia novos modos de ampliação e ressignificação dos universos ficcionais. A partir dos perfis e das indexações os fãs aprofundam os arcos narrativos, completam as lacunas do paratexto e criam versões alternativas da trama. Ao estabelecermos um diálogo entre a literacia midiática e as práticas da cultura de fãs é fundamental ressaltarmos que a reflexão sobre as dimensões analisadas neste trabalho se limita às especificidades do fandom Limantha e aos desdobramentos narrativos propostos por Cao Hamburger.

Os conteúdos publicados no Twitter apresentam diversas camadas interpretativas, reverberando distintas práticas e produções de sentido do fandom. Por exemplo, as discussões sobre o modo como o casal era representado não se limitavam ao microblogging. Muitas vezes um meme postado no Twitter se desdobrava no grupo do WhatsApp e inspirava o início de uma fanfic. Ou seja, o que observamos é que os tópicos repercutidos pelos fãs do shipp eram compostos 
por várias camadas intertextuais, com referências externas e internas à atração da TV Globo.

Embora a emissora crie várias ações de engajamento, os fãs tendem a se engajar a partir de suas próprias estratégias. As indexações são definidas coletivamente e são usadas não só para unificar a conversação em torno de um mesmo tópico, mas para protestar contra os acontecimentos da história. Ao circularem apenas entre o shipp, as hashtags acabavam formando, mesmo que indiretamente, comunidades momentâneas, contribuindo para o aprofundamento do universo ficcional.

Sendo assim, verificamos que a análise dos tweets do fandom Limantha nos ajuda a compreender a pluralidade conversacional dos conteúdos produzidos no Twitter. A produção criativa dos fãs abrange tanto a compreensão crítica da telenovela infanto-juvenil, quanto as características e potencialidades da arquitetura informacional do Twitter na elaboração das estratégias para gerar maior engajamento. Evidenciando desse modo o domínio de diversas competências associadas à literacia midiática e possibilitando a compreensão de novos modos de consumo das telenovelas infanto-juvenis no Brasil.

\section{Referências}

ALVERMANN, D.; HAGOOD, M. Fandom and critical media literacy. Journal of Adolescent \& Adult Literacy, v. 43, n. 5, 2000. Disponível em: https://bit.ly/3chCEzj. Acesso em: 14 abr. 2020.

BORGES, G. et al. Construção de mundos ficcionais pelo fandom Limantha, de Malhação - Viva a diferença. LOPES, M. I. V. (org.). A construção de mundos na ficção televisiva brasileira. Porto Alegre: Sulina, 2019, v. 6.

BORGES, G. et al. Fãs de Liberdade, Liberdade: curadoria e remixagem na social TV. LOPES, M.I.V. de (org.). Por uma teoria de fãs da ficção televisiva brasileira II: práticas de fãs no ambiente da cultura participativa. Porto Alegre: Sulina, 2017. 
BRANDÃO, C. et al. Cultura participativa na esfera ficcional de $O$ Rebu. Lopes, M.I.V. de (org.). Por uma teoria de fãs da ficção televisiva brasileira. Porto Alegre: Sulina, 2015.

BRUNS, A.; MOE, H. Structural layers of communication on Twitter. WELLER, K. et al. (orgs.). Twitter and Society. Peter Lang: Nova York, 2013.

COPPA, F. An archive of our own - Um arquivo só nosso (Escritores de Fanfiction, Uni-vos). JAMISON, A. Fic - Por que a fanfiction está dominando o mundo. Rocco: Rio de Janeiro, 2017.

DINEHART, S. Transmedial play: cognitive and cross-platform narrative, online, 2008. Disponível em: https://bit.ly/2s169jv. Acesso em: 14 abr. 2020.

Fãs de casal lésbico de Malhação receiam término e protestam contra a novela. OBSERVATÓRIO DO CINEMA, online, 2018. Disponível em: https://bit.ly/2ycapUe. Acesso em: 14 abr. 2020.

FECHINE, Y.; CAVALCANTI, G. TV Social em telenovelas da Rede Globo: estratégias e papéis. Lumina, v. 11, n. 2, 2017. Disponível em: https://bit.ly/2Pgtv0C. Acesso em: 14 abr. 2020.

FRAGOSO, S.; RECUERO, R.; AMARAL, A. Métodos de pesquisa para internet. Porto Alegre: Sulina, 2011.

GILSTER, P. Digital literacy. Nova York: John Wile, 1997.

Globo quer 'pegar leve' com Malhação. TV Folha, online, 1995. Disponível em: https://bit.ly/2DdHSQK. Acesso em: 14 abr. 2020. 
GREENHOW, C.; GLEASON, B. Twitteracy: Tweeting as a new literacy practice. In: The Educational Forum, v. 76, n. 4, 2012. Disponível em: https://bit.ly/2N0Mav1. Acesso em: 14 abr. 2020.

HERRERO-DIZ, P. et al. Estudio de las competencias digitales en el espectador fan español. Palabra Clave, v. 20, n. 4, 2017. Disponível em: https://bit.ly/2uMbGPz. Acesso em: 14 abr. 2020.

HIRSJÄRVI, I. Alfabetización mediática, fandom y culturas participativas. Un desafío global. Anàlisi Monogràfic, 2013. Disponível em: https://ddd.uab.cat/ record/112869. Acesso em: 14 abr. 2020.

JAMISON, A. Fic - Por que a fanfiction está dominando o mundo. São Paulo: Rocco, 2017.

JENKINS, $\mathrm{H}$; et al. Cultura da conexão - criando valor e significado por meio da mídia propagável. São Paulo: Aleph, 2014.

JENKINS, H. et al. Confronting the challenges of participatory culture media education for the 21st century. Massachusetts: MIT Press, 2009.

KELLNER, D. ; SHARE, J. Toward critical media literacy: core concepts, debates, organizations, and policy. Journal Discourse: Studies in the Cultural Politics of Education, v. 26, n. 3, 2005. Disponível em: https://bit.ly/3gyd7op. Acesso em: 14 abr, 2020.

LIVINGSTONE, S. Making sense of television - The psychology of audience interpretation. 2a. ed. Nova York: Routledge, 2007. 
MASSAROLO, J.; MESQUISA, D. Narrativa transmídia e a Educação: panorama e perspectivas. Revista Ensino Superior Unicamp, n. 9, 2013. Disponível em: https://bit.ly/2uRaZ51. Acesso em: 14 abr. 2020.

MIHAILIDIS, P. Media literacy and the emerging citizen: Youth, engagement and participation in digital culture. Nueva York: Peter Lang, 2014.

OBSERVATÓRIO DA QUALIDADE NO AUDIOVISUAL. Análise das fanfictions da temporada Viva a diferença de Malhação, online, 2019. Disponível em: https://tinyurl.com/y28j6lt4. Acesso em: 7 jul. 2019.

PASSARELLI, B.; AZEVEDO, J. (orgs.). Atores em rede: olhares luso-brasileiros. São Paulo: Editora Senac, 2010.

PECCOLI, V. Malhação - Viva a diferença chega ao fim com maior ibope desde 2009. TV Foco, online, 2018. Disponível em: https://bit.ly/2IciMyn. Acesso em: 14 abr. 2020.

RECUERO, R. BASTOS, M; ZAGO, G. Análise de redes para mídia social. Porto Alegre: Sulina, 2015.

RECUERO, R. Redes sociais na Internet. Porto Alegre: Sulina, 2009.

RECUERO, R. A conversação em rede: comunicação mediada pelo computador e redes sociais na Internet. $2^{a}$. ed. Porto Alegre: Sulina, 2014.

ROJO, R. Multiletramentos na escola. São Paulo: Parábola, 2012.

SANDVOSS, C. Quando a estrutura e a agência se encontram: os fãs e o poder. Ciberlegenda, v. 1, n. 38, 2013. Disponível em: http://bit.ly/20eTbty. Acesso em: 14 abr. 2020. 
SCOLARI, C. Literacia transmedia na nova ecologia mediática - Livro Branco. Barcelona: Europeans Union Funding for Research \& Innovation, 2018.

SCOLARI, C. Transmedia literacy: informal learning strategies and media skills in the new ecology of communication. Revista Telos, v. 193, n. 1, 2016. Disponível em: https://goo.gl/1KtnZD. Acesso em: 14 abr. 2020.

SIGILIANO, D; BORGES, G. A Rede Globo no ecossistema da Social TV: uma análise sobre as postagens do perfil @redeglobo no Twitter. Intexto, Porto Alegre, n. 36, 2016. Disponível em: https://bit.ly/2EHAg9L. Acesso em: 14 abr. 2020.

SIGILIANO, D. BORGES, G. As discussões sobre The X-Files na Social TV: uma análise do backchannel da décima temporada. Contemporânea, v. 17, n. 1, 2019. Disponível em: https://tinyurl.com/y3j34xhb. Acesso em: 14 abr. 2020.

THOMAS, A. Blurring and breaking through the boundaries of narrative, literacy, and identity in adolescent fan fiction. MICHELE, K; COLIN, L (eds.). A new literacies sampler. Nova York: Peter Lang Publishing, 2017.

Submetido em: 31 ago. 20 | aprovado em: 14 out. 20 